\title{
Aquisição de estruturas possessivas inalienáveis: o caso dos nomes de parte do corpo em inglês americano e português brasileiro
}

\section{Acquisition of inalienable possessive structures: the case of body- part names in American English and Brazilian Portuguese}

Fernanda Mendes

Universidade Estadual de Campinas, Campinas, São Paulo / Brasil fernanda.mds@gmail.com

Resumo: Este estudo testa a aquisição de estruturas de posse inalienável em português brasileiro e inglês americano, assumindo que crianças falantes nativas de inglês americano teriam disponível, num primeiro momento, a mesma gramática disponível para crianças falantes nativas de português brasileiro, em que a leitura inalienável poderia ser vinculada tanto na presença de pronomes possessivos quanto na presença de determinantes definidos com nomes de parte do corpo. Aplicando a Tarefa de Julgamento de Valor de Verdade observou-se que a distinção entre as gramáticas das duas línguas apareceu por volta dos seis anos de idade, quando crianças falantes de inglês americano restringiram o uso do determinante definido de acordo com a gramática alvo, não permitindo o seu uso nas estruturas contendo nomes de partes do corpo, quando foi veiculada a interpretação inalienável. Neste caso, o determinante definido foi substituído pelo pronome possessivo.

Palavras-chave: posse; inalienável; aquisição.

Abstract: The current study tests the acquisition of inalienable possessive structures in Brazilian Portuguese and American English, assuming that American English-speaking children start with the same grammar as 
Brazilian Portuguese-speaking children do. This first grammar would allow inalienable interpretation being carried by possessive pronouns as well as definite determiners introducing body-parts names. Using Truth Value Judgement Task method it is noticed that the difference between Brazilian Portuguese grammar and American English grammar appeared around the age of six, when American English-speaking children approach the target grammar, in which the presence of the possessive pronoun is what allows the inalienable interpretation and the use of definite determiners is restricted to alienable possession constructions with body-parts names.

Keywords: possession; inalienable; acquisition.

Recebido em: 10 de dezembro de 2016 Aprovado em: 19 de abril de 2017

\section{Introdução}

De forma geral, as construções de posse inalienável são definidas como estruturas possessivas especiais em que o possuído e o possuidor estabelecem uma relação de posse que não pode ser transferida a outro possuidor qualquer. Usualmente, essas estruturas contam com nomes de partes do corpo, tais como pernas ou nariz, ou relacionais, como pai e irmãos,${ }^{1}$ e implementam uma relação possessiva, independentemente da presença de um pronome que a expresse - tal como em $O$ Pedro lavou a mão (dele) ou $O$ Pedro abraçou a mãe (dele) ${ }^{2}$

A fim de investigar como esse tipo de construção possessiva se comporta no PB adulto e se desenvolve na gramática infantil, este trabalho se apoia em estudos realizados anteriormente que examinam como esse mesmo tipo de estrutura funciona em outras línguas - não

\footnotetext{
${ }^{1}$ No entanto, apenas os nomes de partes do corpo serão examinados no presente artigo. ${ }^{2}$ É importante observar que estas sentenças, em PB, também podem veicular a interpretação alienável. Ou seja, é possível haver uma leitura em que o objeto possuído a mão (dele) ou a mãe (dele) não pertença ao possuidor disponível na sentença $O$ Pedro. No entanto, esta não é a interpretação requerida na presente discussão sobre inalienabilidade.
} 
necessariamente pertencentes à mesma família -, tais como o francês, o espanhol e o inglês.

Assim, serão apresentadas, ao longo deste artigo, pesquisas que tratam sincronicamente da posse inalienável e da sua aquisição, além de estudos que examinam fenômenos relacionados a ela - tais como a aquisição de determinantes e de Princípios A e B da Teoria da Ligação (CHOMSKY, 1981).

De acordo com esses trabalhos, serão apresentadas as hipóteses e previsões aventadas no presente estudo, a serem avaliadas pelos experimentos aplicados em inglês americano (AE) e português brasileiro (PB), exibidos em seguida.

Na seção 2 a seguir, é apresentado o viés teórico deste artigo, incluindo o que a literatura da área afirma sobre a posse inalienável na gramática adulta e infantil, bem como as hipóteses e previsões da presente pesquisa. Na seção 3, em seguida, é apresentado o viés experimental deste artigo, incluindo a metodologia adotada, os fatores envolvidos e os testes específicos (gerados a partir da combinação desses fatores), os sujeitos participantes, os resultados e a discussão. E, por fim, na seção 4 é traçada a conclusão deste artigo.

\section{Estruturas possessivas inalienáveis: viés teórico}

\subsection{PB adulto: estratégias sincrônicas para a marcação de posse inalienável}

Segundo pesquisas diacrônicas sobre posse inalienável ${ }^{3}$, o pronome clítico dativo de posse não se constitui mais como uma estratégia sintática possível para veicular a interpretação inalienável da estrutura em PB. Atualmente, são empregadas outras estratégias, como o uso do pronome possessivo e do determinante definido, que serão analisadas nesta seção, com foco especial na última, já que essa estratégia é a que parece diferenciar o PB de outras línguas românicas, como o francês e o espanhol, além de o distinguir do AE.

Segundo Guéron (1985), a interpretação inalienável é veiculada quando o sintagma nominal que denota a coisa possuída é uma parte

${ }^{3}$ Ver MENDES, 2012. 
intrínseca do sintagma nominal possuidor, que pode ser o sujeito, como em (1), ${ }^{4}$ ou o dativo possuidor, como (2). ${ }^{5}$

(1) a. Jean lève la main.

b. $O$ João levanta a mão.

(2) a. Je lui ai coupé les cheveux.

b. Eu lhe cortei os cabelos.

Por outro lado, a interpretação alienável é veiculada quando o sintagma nominal que denota a coisa possuída é "disjunto" do sujeito ou do dativo possuidor, como mostram os exemplos do AE em (3). ${ }^{6}$

(3) a. \#John raises the hand.
b. \#I cut the hair for her.

Segundo a classificação proposta pela autora, construções em que o sintagma nominal contendo um nome de parte do corpo e introduzido por um determinante definido está em posição do objeto do verbo, como em (1)-(3), apresentam ambiguidade entre a leitura alienável e a inalienável em línguas como o francês, enquanto, em línguas como o AE, há apenas a leitura alienável disponível. Conforme os exemplos (1b) e (2b), observa-se que os dados do PB se comportam tais quais os do francês com respeito a essa classificação.

No caso do AE, para que a leitura inalienável esteja disponível é preciso que, no lugar do determinante definido, haja um pronome possessivo, ${ }^{7}$ tal como ilustra (4a).

(4) a. John raises his hand.

b. Jean lève sa main.

c. João levanta a mão dele.

${ }^{4}$ Exemplo retirado de GUÉRON, 1985, p. 43.

${ }^{5}$ Exemplo retirado de GUÉRON, 1985, p. 43.

${ }^{6}$ Exemplos retirados de GUÉRON, 1985, p. 43-44.

${ }^{7}$ Para uma análise transformacional dessa estrutura, ver CHOMSKY, 1970, p.200. 
Os exemplos em (4b-c) mostram que essa possibilidade também está disponível no francês e no PB. Portanto, quando a estrutura envolve um pronome possessivo, ambas as leituras, alienável e inalienável, estão disponíveis, já que, em (4), his hand, sa main e a mão dele podem tanto pertencer ao sujeito da sentença - John/Jean/João -, quanto a um outro possuidor qualquer, que pode ter sido mencionado no discurso.

Assim, o Quadro 1 apresenta as leituras veiculadas por cada tipo de determinante que introduz o sintagma nominal contendo o nome possuído em cada língua observada:

QUADRO 1 - Leitura permitida com o determinante: AE e francês/PB

\begin{tabular}{l|c|c}
\hline & Determinante definido & Pronome possessivo \\
\hline Leitura inalienável & $\mathrm{PB} /$ Francês & $\mathrm{PB} /$ Francês e AE \\
\hline Leitura alienável & $\mathrm{PB} /$ Francês e AE & $\mathrm{PB} /$ Francês e AE \\
\hline
\end{tabular}

Segundo a hipótese da autora, a diferença apresentada, contrapondo os dados do $\mathrm{AE}$ aos dados do francês ou do $\mathrm{PB}$, em relação à disponibilidade das leituras inalienável e alienável nos exemplos introduzidos por determinantes definidos seria consequência do valor atribuído a um parâmetro morfofonológico, chamado pela autora de "parâmetro de inclusão de PRO", segundo o qual o determinante definido que constitui o sintagma inalienável pode ser uma anáfora pronominal ou um operador iota.

Como uma anáfora pronominal, ou seja, um pronome sem referência independente, o determinante definido seria responsável pela leitura inalienável vinculada, tal qual ocorre em línguas como o francês ou o PB.

Como um operador iota, ou seja, um operador semântico que representa a parte que denota a unicidade de uma descrição definida isto é, a sua definitude -, o determinante definido seria responsável pela leitura alienável veiculada, tal qual acontece em línguas como o francês, o PB e o AE.

Evidência para esta hipótese, na aquisição, seriam as marcas de concordância (gênero, número e pessoa ${ }^{8}$ ) do determinante. Isto é, se a

\footnotetext{
${ }^{8}$ Segundo Guéron (1985), o determinante definido, nas línguas românicas, tem o traço de $3^{\text {a }}$ pessoa.
} 
língua tem os determinantes morfologicamente marcados, como em (5), o determinante definido pode funcionar, além de como um operador iota, como uma anáfora pronominal.

(5)

$$
\text { a. } o(s)
$$

[3Sg. M.Sg.(P1.)]

b. $a(s)$

[3Sg. F.Sg.(Pl.)] [F.Sg.(Pl.)]
(6)
a. the
boy(s)
[Ø]
[M.Sg.(P1.)]
b. the
$\operatorname{girl}(\mathrm{s})$
[Ø]
[F.Sg.(Pl.)]

[M.Sg.(P1.)]

$\operatorname{garota}(\mathrm{s})$

Por outro lado, se a língua não tem os determinantes morfologicamente marcados, como em (6), o determinante definido não pode atuar como uma anáfora pronominal, mas apenas como um operador iota.

Sendo o determinante definido uma anáfora, Guéron (1985) propõe, como uma das condições sintáticas básicas, que ele se sujeite à ligação anafórica. Ou seja, para que haja a interpretação inalienável é preciso que estas construções estejam submetidas ao Princípio A da Teoria da Ligação, apresentado em (7), conforme exemplo (12A) em Chomsky (1981, p.188). ${ }^{9}$

(7) Princípio A:

"[...] uma anáfora tem que estar ligada em seu domínio de ligação".

De acordo com esse princípio, a anáfora, precisa ter um antecedente que a c-comande e ambos precisam estar contidos no domínio

\footnotetext{
${ }^{9}$ Do original: "An anaphor is bound in its governing category" (p. 188).
} 
de ligação da primeira, sendo domínio de ligação definido como segue em (8), conforme Roberts (1997, p.142, exemplo 21'). ${ }^{10}$

(8) O domínio de ligação de $\alpha$ é o XP mínimo que contém $\alpha$ e a. Um sujeito que é distinto de $\alpha$ e que não contém $\alpha$; ou b. A flexão que atribui Caso Nominativo para $\alpha$

Assim, no exemplo em (1) acima, la main/a mão é uma anáfora e seu antecedente, o sintagma nominal possuidor Jean/O João, além de c-comandar a anáfora, se configura como um sujeito distinto dela que não a contém. Sendo assim, é explicada a impossibilidade da vinculação da leitura inalienável em exemplos como (9) abaixo, já que o Princípio A não seria respeitado.

(9) O dente caiu.

Além disso, é necessário que haja uma cadeia lexical, que Guéron (1985), de acordo com Chomsky (1981), define como:

(10) "[...] um conjunto de dois ou mais nominais relacionados por ligação anafórica e interpretados como um único argumento em LF" (GUÉRON, 1985, p. 44).

De acordo com a autora, todos os tipos de cadeia são afetados pela "Restrição de não-distintividade" enunciada em (11) abaixo, o que a torna uma condição a ser respeitada também para o estabelecimento da interpretação inalienável.

(11) "Se A e B são elos de uma cadeia, então o referente de A é não-distinto do referente de B" (GUÉRON, 1985, p.44).

A junção da noção de cadeia lexical apresentada em (10) com a restrição de não-distintividade enunciada em (11) resulta, segundo

\footnotetext{
${ }^{10}$ Do original: "Binding Domain (Revised) The binding domain (BD) of $\alpha$ is the smallest XP containing $\alpha$ and:

EITHER (a) a subject (distinct from $\alpha$ and which does not contain $\alpha$ )

OR (b) the I that assigns Nominative Case to $\alpha$ " (p. 142).
} 
a autora, em uma simplificação da gramática frente aos modelos propostos anteriormente, fazendo com que nada mais seja necessário gramaticalmente para que se estabeleça uma interpretação inalienável.

Vergnaud e Zubizarreta (1992), no entanto, discordam desta hipótese, já que uma análise baseada na teoria de controle não capturaria certas restrições que se aplicam a essas estruturas. Portanto, eles propõem que a diferença apresentada entre a disponibilidade das leituras alienável e inalienável em AE e francês seja consequência da dupla interpretação que o sintagma nominal definido contendo nomes de partes do corpo, por exemplo, pode veicular. Segundo estes autores, sintagmas nominais definidos e referenciais podem expressar interpretação de token e interpretação de type de acordo com a "Lei de correspondência", apresentada em (12) abaixo.

\section{(12) Lei de correspondência}

"Quando um DP ou um NP denota, o DP denota um token e o NP denota um type"11.

A interpretação de token, que licencia a interpretação alienável, corresponde a um DP que tem por núcleo um determinante substantivo, conforme Longobardi (1994), resultando em um DP "completo". Já a interpretação de type, que licencia a interpretação inalienável, corresponde tanto a um NP nu, quanto a um DP que tem por núcleo um determinante expletivo.

Os autores definem o determinante expletivo como "uma categoria que não tem representação em um certo domínio D"12 (VERGNAUD e ZUBIZARRETA, 1992, p. 595), conforme a definição de "domínio D" adotada em Chomsky (1981, p.324).

Longobardi (1994), propondo um princípio para reger a realização do núcleo da projeção do determinante, apresentado em (13) abaixo, afirma que determinantes definidos podem ser divididos entre determinantes substantivos e determinantes expletivos, podendo ser a última categoria ainda subdividida entre aqueles que introduzem nomes genéricos massivos plurais e aqueles que introduzem nomes próprios.

\footnotetext{
${ }^{11}$ Do original: "Correspondence Law when a DP or an NP denotes, the DP denotes a token and the NP denotes a type" (p. 612, exemplo 45).

${ }^{12}$ Do original: "an expletive in that sense [Chomsky, 1981] is a category that has no representation in domain D" (p. 595).
} 
(13) “A realização fonológica da posição D é licenciada apenas se ela expressa conteúdo semântico ou traços gramaticais, ou como último recurso"13 (p. 654, exemplo 89).

Segundo Castro (2006, 2007), observa-se que, em PB, além de o determinante expletivo, nulo ou lexicalizado ${ }^{14}$, ocorrer introduzindo sintagmas nominais com nomes próprios e nomes genéricos, esses determinantes também podem introduzir sintagmas nominais possessivos $^{15}$ (no caso, sintagmas nominais introduzidos por possessivos simples prenominais), como mostram os exemplos em (14) abaixo.

(14) a. (O) João comprou um livro.

b. (As) crianças gostam de gibis.

c. $(O)$ meu livro foi publicado.

Assim, a interpretação de type estaria disponível para línguas como o PB, que apresentam determinantes expletivos, e não para o $\mathrm{AE}$, na qual este tipo de determinantes não estão presentes ${ }^{16}$, como evidenciam os exemplos em $(15)^{17}$ abaixo.

${ }^{13}$ Do original: "The phonetic realization of the $\mathrm{D}$ position is licensed only if it expresses semantic content or grammatical features, or as a last resort" (p. 654, exemplo 89). ${ }^{14}$ Segundo Castro $(2006,2007)$, no PB o determinante expletivo pode ocorrer tanto nulo quanto lexicalizado, enquanto, no PE, ele ocorre apenas lexicalizado.

${ }^{15}$ Para uma análise diacrônica dessa coocorrência, ver os estudos de Vianna (2004), Floripi (2008) e Rinke (2010).

${ }^{16}$ Segundo Longobardi (1994), há dois casos em AE em que o determinante definido expletivo pode ocorrer: introduzindo sintagmas nominais com nomes genéricos nãomassivos e singulares, como em (i) abaixo (LONGOBARDI, 1994, p. 650, exemplo 80a-b); ou introduzindo sintagmas nominais com adjetivos substantivados genéricos, como em (ii) abaixo (LONGOBARDI, 1994, p.644, exemplo 44a-b).

(i) a. The lion has four legs.

b. *Lion has four legs.

(ii) a. The rich are becoming even richer.

b. *Rich are becoming even richer.

${ }^{17}$ Exemplos retirados de Longobardi (1994, p. 631, exemplo 43), exceto exemplo 39d. 
(15) a. *I love the France.

b. *The beavers are mammals.

c. * The wine is made out of grapes.

d. *The my book was published.

A interpretação de token, por outro lado, estaria disponível para ambos os tipos de línguas, dado que o PB e o AE apresentariam igualmente determinantes substantivos.

Dessa forma, a gramática adulta do AE e do PB apresentariam padrões opostos em relação à leitura permitida quando está presente o determinante definido: enquanto, na primeira, determinantes definidos, por serem substantivos, seriam usados unicamente para denotar a leitura alienável, na segunda, esses mesmos determinantes seriam usados para denotar ambas as leituras, sendo inalienável quando o determinante definido é expletivo e alienável quando o determinante definido é substantivo, como ilustra o Quadro 2 abaixo.

QUADRO 2 - Leitura permitida com o determinante definido: AE e PB

\begin{tabular}{c|c|c}
\hline Língua & Determinante substantivo & Determinante expletivo \\
\hline PB & Leitura alienável & Leitura inalienável \\
\hline $\mathbf{A E}$ & Leitura alienável & Não se aplica \\
\hline
\end{tabular}

Já o uso dos pronomes possessivos, por outro lado, desencadearia, em ambas as línguas, as leituras alienável e inalienável, sendo, porém, em AE, a única opção no caso da última.

Vergnaud e Zubizarreta (1992) se apoiam ainda na dependência semântica. Segundo essa noção, o objeto inalienável é uma entidade dependente, já que ele é inerentemente definido em termos de outro objeto do qual faz parte. Contrariamente, o objeto alienável é uma entidade independente, isto é, tem definição própria.

Dessa forma, os autores assumem que um nome inalienável, diferentemente de um nome alienável, tome um argumento possuidor, que pode ser lexicalizado dentro ou fora do sintagma nominal. Logo, nomes de partes do corpo, por exemplo, teriam duas entradas lexicais: 

(16) a. mão (x)
b. mão

Uma em que ele toma um argumento possuidor e veicula a leitura inalienável, como em (16a), e outra em que ele não toma um argumento possuidor e veicula a leitura alienável, como em (16b) (Cf. AUTHIER, 1988; TELLIER, 1988 apud VERGNAUD; ZUBIZARRETA, 1992).

\subsection{PB infantil: posse inalienável e determinantes definidos}

Baseando-se nas análises exibidas na seção anterior para a gramática adulta do PB, nesta seção, serão apresentados alguns estudos, dentro dessa mesma língua, ou ainda examinando outras línguas, tais como o holandês, o espanhol e o AE, que tratam da gramática infantil focando na aquisição da posse inalienável juntamente com outros tipos de estruturas relacionadas diretamente a ela, como determinantes definidos.

Ramos (1999 apud PÉREZ-LEROUX et al., 2002a, b), examinando a interpretação de determinantes definidos em contextos de posse inalienável na gramática de crianças com DEL, ${ }^{18}$ observa, de acordo com os resultados das crianças típicas falantes de AE, uma taxa decrescente na veiculação da leitura inalienável em estruturas em que está presente o determinante definido. Enquanto é encontrada uma taxa de $30 \%$ nos resultados do grupo mais jovem - 3;8 a 4;5 anos -, no grupo mais velho - 4;7 a 5;7 anos -, é encontrada uma taxa de $23 \%$.

Resultados semelhantes podem ser encontrados em Baauw (2000), reportado em Schaeffer (2002), que examina o comportamento do determinante definido durante a aquisição de estruturas de posse inalienável em duas línguas distintas parametricamente, o holandês e o espanhol. Embora, na gramática alvo dessas línguas, o determinante definido exiba a possibilidade de veicular a leitura inalienável apenas em espanhol, na gramática infantil, essa vinculação é possível em ambas as línguas.

De acordo com o experimento de Julgamento de Valor de Verdade realizado pelo autor, envolvendo 47 crianças falantes nativas de holandês, de 4;0 a 7;0 anos de idade, e 22 adultos, também falantes nativos dessa mesma língua, observou-se que adultos e as crianças

${ }^{18}$ Déficit Específico da Linguagem. 
pertencentes ao grupo mais velho - de 6;0 a 7;0 anos - apresentam 70\% de rejeição em relação à presença do determinante definido em construções inalienáveis, enquanto as crianças do grupo mais jovem - 4;0 a 5;0 anos -, embora exibam a mesma tendência, a fazem em proporções menores, apresentando 30\% de rejeição em relação à mesma estrutura. Dentre os resultados do espanhol, a leitura inalienável é aceita na presença do determinante definido tanto por parte das crianças quanto por parte dos adultos.

Segundo o autor, a interpretação de determinantes definidos é afetada por dois fatores, um de ordem pragmática, em que as crianças apresentariam dificuldades para restringir o uso de determinantes aos contextos nos quais eles são permitidos na gramática alvo, e outro de ordem morfossintática, segundo o qual a aquisição incompleta dos traços morfossintáticos do núcleo $\mathrm{D}$ faria com que eles pudessem ser tratados como determinantes expletivos em holandês.

Pérex-Leroux et al. (2002a, b), que se baseiam nos estudos supracitados, realizam um estudo comparativo entre as gramáticas do $\mathrm{AE}$ e do espanhol, observando a interpretação de determinantes definidos no mesmo contexto possessivo. É observado que, tal qual a gramática adulta do holandês, a do AE não apresenta a possibilidade de existir a leitura inalienável com estruturas nas quais ocorre o determinante definido, como já discutido anteriormente neste capítulo, enquanto na gramática infantil pode ser observada essa veiculação.

No entanto, diferentemente de Baauw (2000), esses autores adotam a hipótese distribucional, segundo a qual "formas com distribuição morfossintática comparável competem lexicalmente por um dado espaço semântico"19 (PÉREZ-LEROUX et al., 2002b, p. 199).

Assim, os autores assumem que, tanto no AE quanto no espanhol, as crianças incluiriam entre as representações semânticas do determinante definido a construção inalienável, porque haveria uma supergeneralização do uso de determinantes definidos na gramática inicial ${ }^{20}$, mas não

\footnotetext{
${ }^{19}$ Do original: "forms with comparable morphosyntactic distribution lexically compete for a given semantic space", p. 199.

${ }^{20}$ Ver de Villiers e Roeper, 1995, Mathewson et al., 2001, Pérez-Leroux et al., 2004, Schaeffer e Mathewson, 2005, Munn et al., 2006, entre outros, para estudos mais aprofundados sobre a aquisição de determinantes definidos em AE - comparados a outras línguas.
} 
por dificuldades pragmáticas, já que isso seria observado mesmo em contextos discursivos e pragmáticos cuidadosamente controlados, ou por fatores morfossintáticos, dado que isso também seria notado em contextos controlados, mas pelo fato de que "eles ainda não teriam aprendido todas as restrições impostas pelas formas concorrentes em contextos particulares"21 (PÉREZ-LEROUX et al., 2002a, p. 246).

Segundo Pérez-Leroux et al. (2002a), crianças falantes de línguas como o AE teriam que aprender que determinantes definidos podem ocorrer quando o referente do sintagma nominal que ele introduz pode ser identificado no discurso, é único e é máximo, tal qual em $(17)^{22}$ abaixo.

(17) The students entered the room.

Por violarem a condição de identificação no discurso, e maximalidade, no caso de (18b), os exemplos em (18) ${ }^{23}$, contendo nomes abstratos, como em (18a), construções de posse inalienável, como em (18b), e plurais genéricos, como em (18c), não seriam permitidos nesta língua.

(18) a. * The freedom depends on the development of civil society.

b. \#The teachers shook the head.

c. \#The pandas are not related to bears

No entanto, contextos particulares, exemplificados em $(19)^{24}$, como construções genéricas no singular, em (19a), e construções de posse inalienável dentro de sintagmas preposicionais, como em (19b), embora violem as mesmas condições violadas pelos exemplos acima, são permitidas em AE.

(19) a. The lion lives in Africa.

b. They were hit in the arm.

\footnotetext{
${ }^{21}$ Do original: "they haven't yet learned all the restrictions imposed by the competing forms in particular contexts", p.246.

22 Pérez-Leroux et al., 2002a, p. 246, exemplo 1.

${ }^{23}$ Pérez-Leroux et al., 2002a, p. 246, exemplos 2-4.

${ }^{24}$ Pérez-Leroux et al., 2002a, p. 247, exemplo 5.
} 
Assim, crianças falantes do AE teriam que, em algum momento durante o desenvolvimento linguístico, restringir esta opção de acordo com os dados de input, ou seja, permitir apenas a construção alienável na presença deste determinante. Segundo Pérez-Leroux et al. (2002b), as evidências para isso estariam relacionadas às propriedades do sistema de possessivos do $\mathrm{AE}$ - que se opõem àquelas apresentadas pelo sistema do espanhol - dado que esses seriam dados mais robustos em comparação àqueles que dizem respeito às propriedades dos determinantes definidos.

Para testar a hipótese distribucional Pérez-Leroux et al. (2002a, b) aplicaram um experimento de compreensão (act-out), envolvendo, por um lado, 17 crianças falantes nativas de AE, de 3;11 a 6;6 anos de idade, e 18 adultos, como grupo controle; e por outro, 20 crianças falantes de espanhol, de 3;2 a 6;7 anos de idade, e 8 adultos, como grupo controle.

De acordo com os resultados obtidos, crianças falantes de AE pertencentes ao grupo mais jovem - nove crianças de 3;11 a 5;2 anos - permitem que a leitura inalienável seja vinculada por estruturas contendo o determinante definido mais frequentemente do que as crianças pertencentes ao grupo mais velho - oito crianças de 5;5 a 6;6 anos -, enquanto adultos não permitem essa vinculação, confirmando empiricamente a evidência assumida na pesquisa. Já em relação aos resultados do espanhol, tal qual aqueles observados em Baauw (2000), a leitura inalienável é aceita com o determinante definido tanto na gramática infantil quanto na gramática adulta.

Por fim, em relação ao PB, Mendes (2010) realiza uma pesquisa de caráter longitudinal, examinando diferentes faixas etárias de três crianças - AC, G e R - passando pela fase de aquisição dessa estrutura de posse.

De acordo com os resultados gerais dessa pesquisa, observase que, em $82 \%$ dos dados, o possuidor encontra-se no discurso e não na sentença, diferentemente do que propõem os estudos apresentados anteriormente - especialmente em relação àqueles que tratam de nomes de partes do corpo.

No entanto, a autora observa que, nas faixas etárias mais jovens, as crianças produzem muitos DPs soltos, o que poderia explicar essa não submissão à dependência referencial.

Por outro lado, é observado um padrão crescente com relação à presença do possuidor na sentença à medida que a criança se torna mais velha, além de, na presença do possuidor, as exigências de dependência 
referencial passarem a ser respeitadas, indicando que, à medida que a gramática vai convergindo, vai sendo submetida às regras presentes na gramática adulta.

\subsection{Hipóteses e previsões para a aquisição de posse inalienável}

De acordo com os estudos experimentais acerca da aquisição de estruturas de posse inalienável apresentados anteriormente, a presente pesquisa assume a hipótese distribucional de Pérez-Leroux et al. (2002a, b, 2004), segundo a qual a superextensão do uso do determinante definido em línguas como o AE seria explicada pela restrição tardia dos contextos particulares nos quais esse determinante específico pode ocorrer nessa língua - que seriam um subconjunto dos contextos permitidos em línguas como o $\mathrm{PB}$, que, por sua vez, não teriam que realizar esse mesmo tipo de restrição.

Fatores que contribuiriam para essa restrição tardia no $\mathrm{AE}$ constituem as propriedades das quais dependem as construções possessivas inalienáveis e seguem elencados em (I)-(II) abaixo.

(I) Tipo da categoria vazia do possuidor: anafórica $v s$ pronominal

(II) Tipo de determinante: possessivo $v s$ definido (substantivo $v s$ expletivo)

Com respeito à propriedade em (I), a categoria vazia do possuidor do sintagma nominal possuído contendo o nome inalienável - conforme o seu traço [ \pm lexical] (BARKER, 1995) - ou o nome que permite estabelecer uma relação inalienável - conforme o seu traço [ \pm relacional] (LICHTENBERK et al., 2011) - pode ser de duas naturezas, ou anafórica ou pronominal, a depender do tipo de nome envolvido/relação que ele estabelece.

Sendo um nome de parte do corpo (que estabeleça uma relação parte-todo), essa categoria é anafórica, obedecendo ao Princípio A da Teoria da Ligação, já que se trataria de um vestígio fruto de movimento, como em (20) abaixo.

(20) a. O Pedro ${ }_{j}$ disse que o João lavou a mão $t_{\mathrm{i}}$.

b. O Pedro disse que os cabelos incomodaram o João $_{\mathrm{i}}$. 
Semelhante ao que ocorre no caso de a categoria vazia ser pronominal ${ }^{25}$, tratando-se da propriedade em (II), quando o sintagma nominal que contém o nome de parte do corpo, como nos exemplos em (21), é acompanhado por um pronome possessivo, se sujeitaria ao Princípio B.

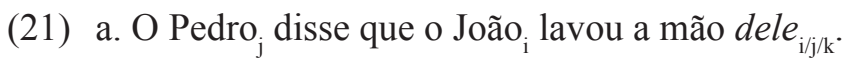

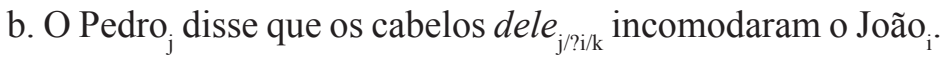

Em relação aos exemplos (21b), observa-se que a ligação entre o sintagma nominal possuído os cabelos dele e João não seria estabelecida porque não haveria c-comando. ${ }^{26}$

Ainda em relação à propriedade em (II), tem-se os pronomes possessivos, que não apresentariam distinção nas leituras que podem ser vinculadas em $\mathrm{PB}$ ou em AE, embora apresentem diferentes estruturas sintáticas.

Além desses, tem-se os determinantes definidos, que apresentam padrões opostos em relação às leituras permitidas nessas duas línguas quando ele introduz o sintagma possuído que contém nomes potencialmente inalienáveis. Enquanto, em AE, eles seriam usados unicamente para denotar a leitura alienável, em $\mathrm{PB}$, seriam usados para ambas as leituras.

De acordo com Vergnaud e Zubizarreta (1992), essa ambiguidade no PB seria explicada pelo fato de os determinantes definidos, nesta língua, se dividirem entre determinantes definidos substantivos e determinantes definidos expletivos. Enquanto os primeiros disponibilizariam a leitura alienável, os últimos disponibilizariam a leitura inalienável. E, pelo fato de o AE não apresentar determinantes expletivos - exceto por dois casos específicos já esclarecidos anteriormente e retomados mais adiante -, consequentemente, também não permitiria a leitura inalienável sendo vinculada por sintagmas nominais introduzidos por determinantes definidos, tal como resume o Quadro 3 abaixo.

\footnotetext{
${ }^{25}$ Quando se trata de nomes relacionais.

${ }^{26}$ Fato apontado por Grolla (c.p.).
} 
QUADRO 3 - Leitura permitida de acordo com tipos de determinantes: AE e PB

\begin{tabular}{l|c|l|l}
\hline \multirow{2}{*}{ Língua } & \multicolumn{2}{|c|}{ Determinante definido } & \multirow{2}{*}{ Pronome possessivo } \\
\cline { 2 - 3 } & Substantivo & \multicolumn{1}{c}{ Expletivo } & \\
\hline PB & Leitura alienável & Leitura inalienável & Leitura (in)alienável \\
\hline AE & Leitura alienável & Não se aplica & Leitura (in)alienável \\
\hline
\end{tabular}

Assumindo-se, de acordo com Vergnaud e Zubizarreta (1992), que determinantes definidos substantivos permitem a interpretação token do sintagma nominal e, portanto, a leitura alienável e que determinantes definidos expletivos permitem a interpretação type do sintagma nominal e, portanto, a leitura inalienável, assume-se que a aquisição da posse inalienável seja dependente da aquisição de determinantes substantivos e expletivos.

Assim, enquanto a gramática infantil do $\mathrm{AE}$ não restringe os contextos particulares em que os determinantes definidos expletivos podem aparecer - a saber, em genéricos singulares, como em (22) abaixo, chamados por Vergnaud e Zubizarreta de protótipos, ou seja, tokens que veiculam o traço [ \pm espécie], e dentro de sintagmas preposicionais locativos, como em (23) abaixo -, eles seriam admitidos como substantivos e expletivos, apresentando um comportamento semelhante ao do PB.

(22) The Bengal tiger is becoming extinct.

(23) John hit him on the face.

No entanto, as evidências relevantes a favor da falta de determinantes expletivos nesta língua estariam relacionadas ao paradigma possessivo - em que os possessivos funcionam como determinantes -, como em (24) abaixo, e à impossibilidade de haver determinantes definidos introduzindo nomes próprios, como em (25).

(24) (*The) My book is blue.

(25) (*The) John is reading. 
Prevê-se, portanto, que crianças mais jovens falantes de AE apresentem o mesmo padrão das crianças e adultos falantes de $\mathrm{PB}$, isto é, que haja uma tendência maior à aceitação de determinantes definidos coocorrendo com a leitura inalienável e uma tendência maior à aceitação de pronomes possessivos coocorrendo com a leitura alienável.

Por outro lado, crianças mais velhas falantes de AE se aproximariam do padrão apresentado por adultos falantes de AE, no qual determinantes definidos coocorrem com a leitura alienável, enquanto pronomes possessivos coocorrem com a leitura inalienável.

De acordo com o que foi discutido nesta seção, é apresentado, na Figura 1 abaixo, um esquema que resume as relações estabelecidas entre a leitura veiculada e o tipo de determinante, além de os Princípios da Ligação envolvidos, nas construções de posse em AE e PB.

FIGURA 1 - Resumo dos sistemas: PB e AE

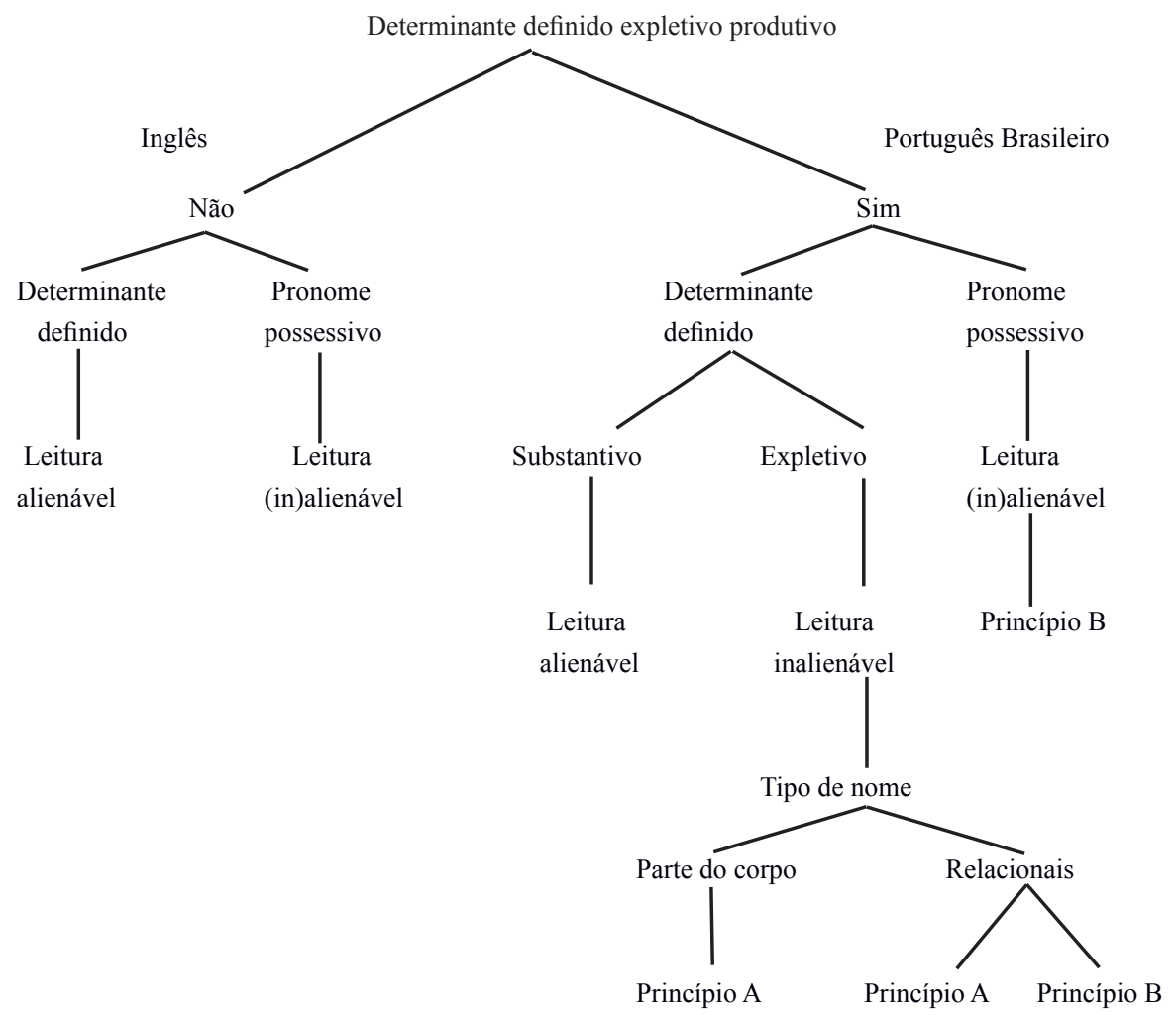


Assim, enquanto crianças falantes de $\mathrm{AE}$ não restringirem os determinantes definidos expletivos aos contextos particulares em que eles são permitidos, a sua gramática estará submetida às condições da gramática de línguas como o PB.

\section{Estruturas possessivas inalienáveis: viés experimental}

\subsection{Metodologia}

Para investigar construções de posse inalienável quantificadas de forma experimental, a fim de examinar como esse tipo de estrutura se desenvolve na gramática infantil, em comparação ao seu comportamento apresentado na gramática adulta, realizou-se uma coleta transversal de dados infantis, caracterizada por Scarpa (2001, p. 204) como uma técnica de recolhimento de dados provenientes de um número alto de informantes em que as faixas etárias observadas são previamente especificadas de acordo com os achados de estudos anteriores, permitindo testar com maior profundidade certos aspectos do objeto em questão, uma vez que as estruturas estudadas dispõem de uma complexidade maior para a sua produção.

Adotando-se a técnica da Tarefa de Julgamento de Valor de Verdade (TJVV), definida por Gordon (1996) como um método que "requer que a criança simplesmente faça um julgamento bipolar sobre se uma declaração descreve com precisão uma situação particular, em alusão a algum contexto ou preâmbulo" (p. 211), testa-se a compreensão de falantes de AE e de PB em relação à ocorrência de determinantes definidos e pronomes possessivos em estruturas de posse em que ambas as leituras alienável e inalienável estariam disponíveis, como será detalhado na subseção seguinte, uma vez que se espera que haja uma restrição tardia no $\mathrm{AE}$ dos contextos particulares em que é permitido o uso do determinante definido, fazendo com que a gramática infantil do $\mathrm{AE}$ se assemelhe com a gramática do $\mathrm{PB}$ e não com a do $\mathrm{AE}$ adulto.

Para a elaboração do experimento geral, foram selecionados quatro fatores, apresentados em (26) abaixo, sendo (26a-b) referentes à sentença-teste, (26c) relacionado à imagem que acompanha a sentençateste e (26d) condizente à interação entre a sentença-teste e a imagem que a acompanha. 
(26) a. Tipo de determinante: artigo definido ou pronome possessivo

b. Função sintática: objeto direto, sujeito da passiva, complemento do sintagma preposicional.

c. Tipo de imagem: favorável à leitura alienável ou favorável à leitura inalienável

d. Interpretação possessiva: alienável ou inalienável

Da interação entre os fatores (26a) e (26d), que compõem o experimento geral, resultam quatro pequenos testes, explicitados em (27) abaixo, que foram utilizados aqui para apresentar de forma didática os resultados dessa pesquisa, sendo que cada um deles contém de uma a três sentenças-teste (que coocorrem com as imagens descritas acima), e cada um dos testes interage independentemente com o fator apresentado em (26b), já que se espera ver se existe algum efeito decorrente da função sintática em que se encontra a estrutura inalienável, dado que questões de c-comando podem influenciar os resultados.

(27) a. Definido \& Inalienável

b. Definido \& Alienável

c. Possessivo \& Inalienável

d. Possessivo \& Alienável

Assim, foram conduzidos dois estudos, um em inglês e outro em português, com o mesmo material. Sendo quatro pequenos testes independentes, dois com artigos definidos (um com imagens favoráveis a leitura inalienável, outro com imagens favoráveis à leitura alienável) e dois com possessivos (também com imagens favoráveis cada tipo de leitura).

\subsection{Método}

Em relação aos dados infantis coletados do $\mathrm{AE},{ }^{27}$ participaram dos testes apresentados acima 45 crianças falantes nativas, todas estudantes

\footnotetext{
${ }^{27}$ A aplicação dos testes foi permitida mediante autorização dada pela comissão de ética do Departamento de Linguística da University of Massachusetts at Amherst. Além desta, cada uma das escolas também autorizou a pesquisa e, por fim, os pais de cada uma das crianças assinaram um Termo de Consentimento Livre e Esclarecido autorizando a participação delas nos experimentos, bem como a utilização dos seus dados na presente pesquisa.
} 
de escolas infantis ${ }^{28}$ das cidades de Amherst, Sunderland e Northampton - localidades pertencentes ao estado de Massachusetts, nos EUA. Sendo o grupo de crianças mais jovens composto por 30 crianças de 3;03 a 5;11 - média etária de 4;07 - e o grupo de crianças mais velhas composto por 15 crianças de 6;01 a 8;04 - média etária de 7;02.

Além disso, como grupo controle adulto, os mesmos testes foram aplicados a 13 adultos falantes nativos de AE, sendo todos estudantes de graduação da University of Massachusetts at Amherst, EUA.

Já com respeito aos dados infantis coletados do $\mathrm{PB}^{29}$, foi aplicada a mesma série de testes em 79 crianças falantes nativas, todas estudantes de escolas infantis ${ }^{30}$ das cidades de Campinas, SP. Sendo o grupo de crianças mais jovens composto por 33 crianças de 3;11 a 5;10 - média etária de 4;11 - e o grupo de crianças mais velhas composto por 46 crianças de 6;00 a 9;00 - média etária de 7;06.

Além disso, como grupo controle adulto, os mesmos testes foram aplicados a 15 adultos falantes nativos de PB, sendo todos estudantes universitários da Universidade Federal de Santa Catarina e da Universidade Estadual de Campinas.

Em relação ao material, foi utilizado um computador portátil, contendo as apresentações em forma de .ppt pertencentes aos testes aplicados, e formulários para anotar as respostas fornecidas pelos informantes.

Assim, foram contadas três histórias em que um garoto - nas duas primeiras histórias - e uma garota - na última história - brincavam com o(a) Senhor(a) Cabeça de Batata enquanto faziam outras atividades,

${ }^{28}$ Center for Early Education and Care, em Amherst; Sunderland Elementary School, em Sunderland; e Bridge Street School, em Northampton.

${ }^{29}$ A aplicação dos testes foi permitida mediante autorização dada pelo Comitê de Ética em Pesquisa (CEP) - vide o Certificado de Apresentação para Apreciação Ética (CAAE) $n^{\circ}$ 13530014.4.0000.5404 identificando a presente pesquisa, disponível online no site da Plataforma Brasil. Além disso, cada uma das escolas também autorizou a aplicação dos testes e, por fim, os pais de cada uma das crianças assinaram um Termo de Consentimento Livre e Esclarecido autorizando a participação delas nos experimentos, bem como a utilização dos seus dados nesta pesquisa. No caso dos adultos, um Termo de Consentimento Livre e Esclarecido também foi assinado pelos próprios participantes autorizando a aplicação dos testes e a utilização dos seus dados neste trabalho.

${ }^{30}$ Escola Municipal de Educação Infantil Agostinho Páttaro, em Campinas; Escola Estadual Maria Alice Colevati Rodrigues, em Campinas. 
como se lavar, se secar e comer, que também implicavam na participação do brinquedo (ou das suas partes).

$\mathrm{Na}$ fase dos testes, cada história contada foi ilustrada por uma série de fotografias apresentadas em slides, que variavam com respeito à leitura que veiculavam, bem como as sentenças-teste variavam em relação ao tipo de determinante presente.

Assim, para cada uma das sentenças-teste contendo determinante definido, como em (28), (29) e (30) abaixo, foi apresentada, por exemplo, uma fotografia veiculando a interpretação inalienável - ou seja, uma fotografia em que o personagem estivesse executando a ação numa parte do próprio corpo e não em uma parte solta do corpo do(a) $\operatorname{Sr}(a)$. Cabeça de Batata, que também se encontrava presente na cena-, como ilustram as Figuras 2, 3 e 4 a seguir.

(28) a. Is Bill cleaning the hands?

b. O Pedrinho está limpando as mãos?

(29) a. Were the eyes being dried?

b. Os olhos estão sendo secos?

(30) a. Did the fly land on the nose?

b. A mosca pousou no nARIZ?

FIGURA 2 - Objeto direto

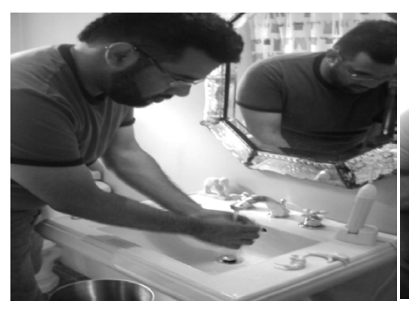

FIGURA 3 - Sujeito da passiva

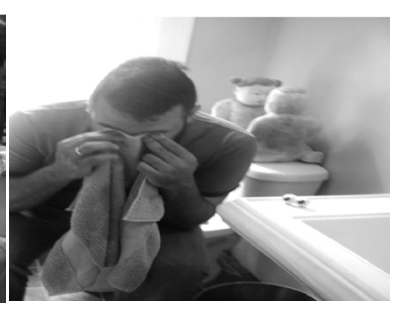

FIGURA 4 - Complemento de PP

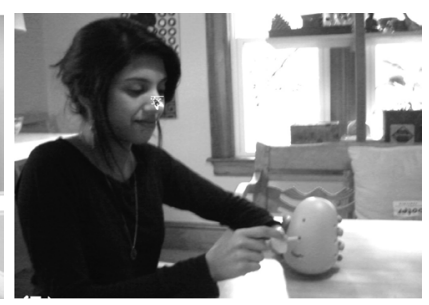

Por outro lado, sentenças-teste contendo determinante definido também coocorreriam com uma fotografia veiculando a interpretação alienável - isto é, uma fotografia em que o personagem estivesse executando a ação numa parte do corpo solta do(a) Sr(a). Cabeça de 
Batata, presente na cena, e não numa parte do próprio corpo -, como mostram os exemplos em (31), (32) e (33) abaixo, ilustrados pelas Figuras 5,6 e 7 a seguir.

(31) a. Is Bill cleaning the nose?

b. O Pedrinho está limpando $o$ nariz?

(32) a. Was the tongue being dried?

b. $A$ língua está sendo seca?

(33) a. Did the fly land on the hat?

b. A mosca pousou no chapéu?

FIGURA 5 - Objeto direto

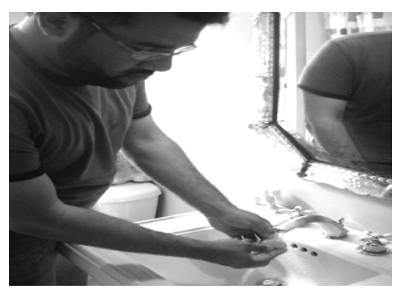

FIGURA 6 - Sujeito da passiva

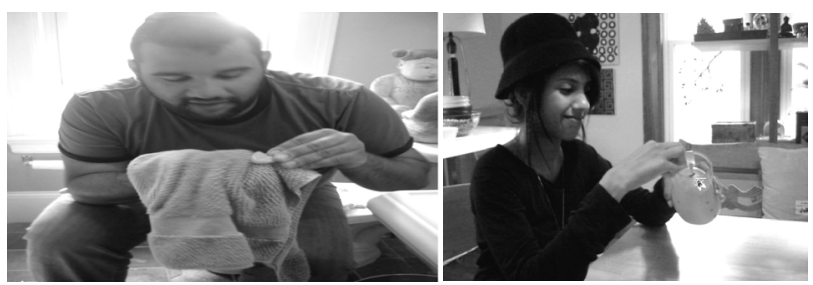

Semelhante às sentenças-teste contendo determinantes definidos, as sentenças-teste contendo pronomes possessivos ${ }^{31}$ poderiam coocorrer com, por exemplo, uma fotografia veiculando a interpretação inalienável - na qual o personagem estivesse executando uma ação numa parte do próprio corpo e não em uma parte do corpo solta do(a) $\operatorname{Sr}(a)$. Cabeça de Batata -, como nos exemplos em (34), (35) e (36) abaixo, ilustrados pelas Figuras 8, 9 e 10 a seguir.

(34) a. Is Bill cleaning his hand?

b. O Pedrinho está limpando a mão dele?

\footnotetext{
${ }^{31} \mathrm{~A}$ forma dele/dela, no teste contendo possessivo em $\mathrm{PB}$, foi utilizada no lugar de seu/ sua porque aquela é a forma preferida na gramática adulta falada desta língua quando presentes antecedentes referenciais, como é o caso das sentenças-teste. Seu/sua seria a forma favorecida no caso de antecedentes genéricos.
} 
(35) a. Was his nose being dried?

b. O nariz dele está sendo seco?

(36) a. Did she drop ketchup on her glasses?

b. Ela derramou catchup nos óculos dela?

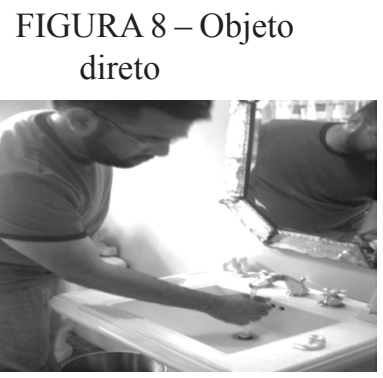

FIGURA 9 - Sujeito da passiva

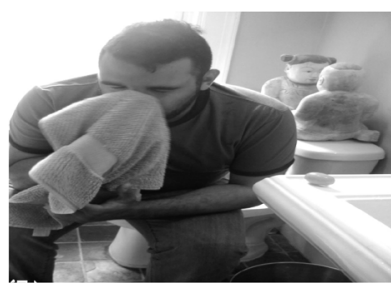

FIGURA 10 - Complemento de PP

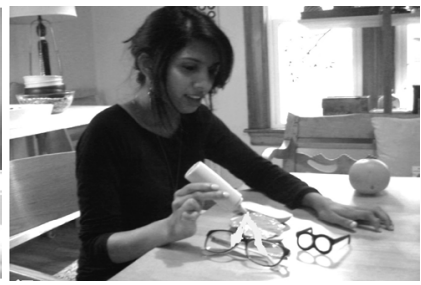

Ou ainda, as sentenças-teste contendo pronomes possessivos poderiam coocorrer com uma fotografia veiculando a interpretação alienável - na qual o personagem estivesse realizando uma ação numa parte do corpo solta do(a) $\operatorname{Sr}(a)$. Cabeça de Batata e não numa parte do próprio corpo -, como mostram os exemplos em (37), (38) e (39) abaixo, ilustrados pelas Figuras 11, 12 e 13 a seguir.

(37) a. Is Bill cleaning his eyes?

b. O Pedrinho está limpando os olhos dele?

(38) a. Was his ear being dried?

b. A orelha dele está sendo seca?

(39) a. Did the fly land on her hair?

b. A mosca pousou no cabelo dela? 
FIGURA 11 - Objeto direto

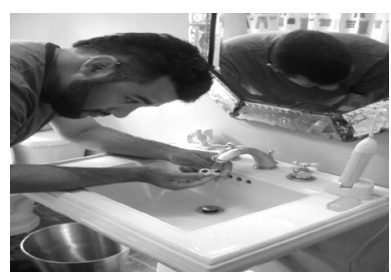

FIGURA 12 - Sujeito da passiva

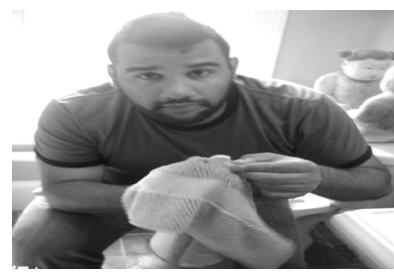

FIGURA 13 - Complemento de PP

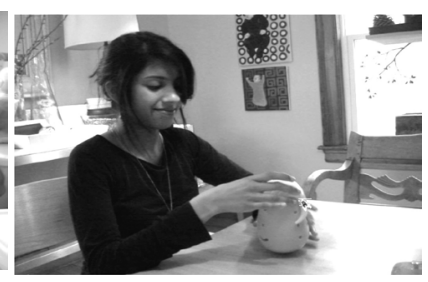

Aplicando essa série de experimentos, de acordo com a técnica de TJVV, foi possível verificar o julgamento do participante acerca da adequação da interpretação favorecida pela fotografia àquela veiculada pela sentença-teste, que, neste caso, se apresentava em forma de pergunta sim-não.

\subsection{Resultados e discussão}

Os resultados gerais seguem de acordo com os quatro testes resultantes da combinação de fatores usados na elaboração do experimento geral, explicitadas na subseção 3.1 acima, e sua interação com o fator idade, qual seja, crianças jovens, crianças velhas e adultos, e tem por base o exame de respostas esperadas em cada um dos testes.

No Teste 1, o uso do determinante definido coocorrendo com este tipo de interpretação possessiva não seria permitido em $\mathrm{AE}$, independentemente da função sintática sob a qual o sintagma possuído aparece.

Já em PB, essa coocorrência é permitida, desde que a categoria vazia de possuidor do sintagma possuído esteja ligada ao seu antecedente respeitando as exigências do Princípio A. Logo, espera-se que haja um resultado diferenciado em relação aos dados com o sintagma possuído desempenhando a função de sujeito da passiva.

Conforme os dados apresentados no Gráfico 1 abaixo, referente aos resultados do AE, observa-se uma taxa de respostas esperadas - no caso, não - bastante baixa nos resultados infantis, frente aos resultados adultos, que apresentam uma taxa mais elevada. 
GRÁFICO 1- Teste 1: AE

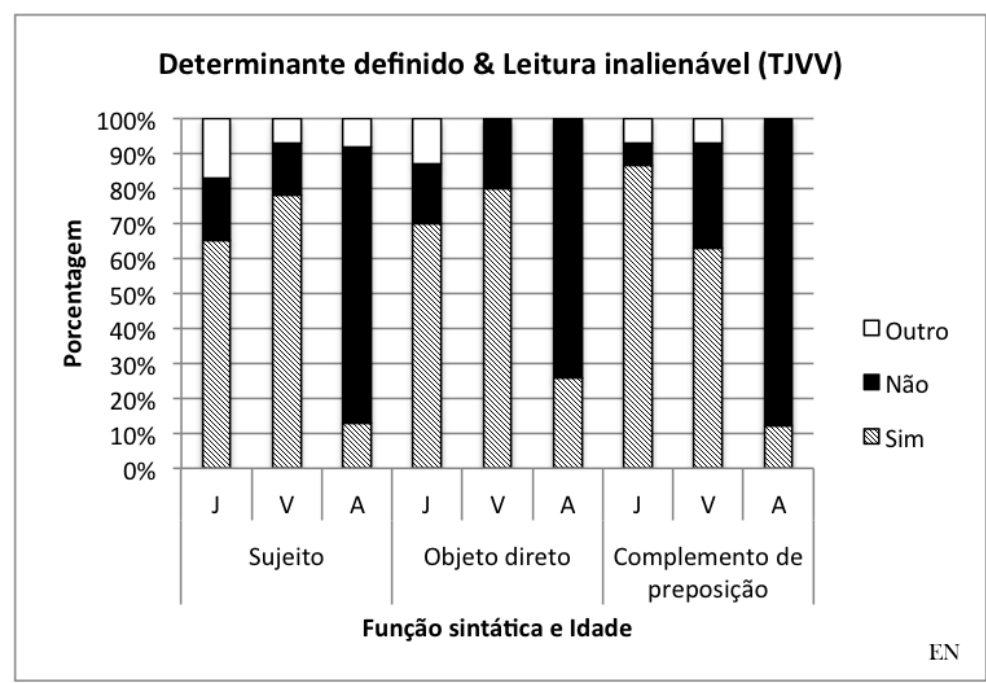

Legenda: J crianças mais jovens

$\mathrm{V}$ crianças mais velhas

A adultos

EN inglês americano

Segundo o gráfico acima, a gramática das crianças mais jovens e a das mais velhas apresentam uma taxa de respostas esperadas bastante próximas - sendo de $18 \%$ e $15 \%$ na função de sujeito da passiva e $17 \%$ e $20 \%$ na função de objeto direto -, exceto quando o sintagma possuído figura na função de complemento da preposição, em que essa taxas são de $6,5 \%$ na gramática das crianças mais jovens e $30 \%$ na gramática das crianças mais velhas.

Essas diferenças percentuais são confirmadas como estatisticamente significativas conforme os resultados do Teste Exato de Fischer, exibidos na Tabela 1 abaixo. 
TABELA 1 - Teste 1 : valor de $p, \mathrm{AE}^{32}$

\begin{tabular}{c|ccc}
\hline \begin{tabular}{c} 
Sujeito da passiva \\
Jovens \\
Velhas \\
\cline { 2 - 3 } Adultos
\end{tabular} & Jovens & Velhas & Adultos \\
\cline { 2 - 4 } & - & 0,63240000 & 0,00000000 \\
\hline Objeto direto & & - & 0,00000000 \\
Jovens & Jovens & Velhas & - \\
Velhas & - & 1,00000000 & 0,00000001 \\
Adultos & & - & 0,00000075 \\
\hline $\begin{array}{c}\text { Complemento } \\
\text { de preposição } \\
\text { Jovens }\end{array}$ & Jovens & Velhas & - \\
Velhas & - & 0,00771100 & 0,00000000 \\
Adultos & & - & 0,00002722 \\
\hline
\end{tabular}

Dessa forma, quando nomes de partes do corpo coocorrem com determinantes definidos neste tipo de estrutura possessiva, observa-se que, enquanto a gramática adulta do AE permite apenas a leitura alienável, indicando o uso do determinante definido substantivo, a gramática infantil permite ambas as leituras - alienável e inalienável -, indicando o uso de ambos os tipos de determinantes definidos - substantivo e expletivo.

À medida que a criança fica mais velha, nota-se uma restrição com relação ao uso de um dos tipos de determinante coocorrendo com a leitura inalienável, apontando uma mudança em direção à gramática alvo, conforme mostram os resultados na função de complemento do sintagma preposicional.

Em relação aos resultados do $\mathrm{PB}$ adulto e infantil, observa-se, de acordo com o Gráfico 2 abaixo, uma taxa bastante alta de respostas esperadas - neste caso, sim - quando o sintagma possuído desempenha as funções de complemento. Porém, quando o sintagma possuído é realizado

${ }^{32}$ As células sombreadas das tabelas contendo o valor de $p$ indicam as diferenças estatisticamente significativas, de acordo com o Teste Exato de Fisher. 
na função de sujeito da passiva, é notada uma baixa taxa de respostas esperadas - no caso, não - na gramática de todos os grupos analisados.

GRÁFICO 2 - Teste 1, PB

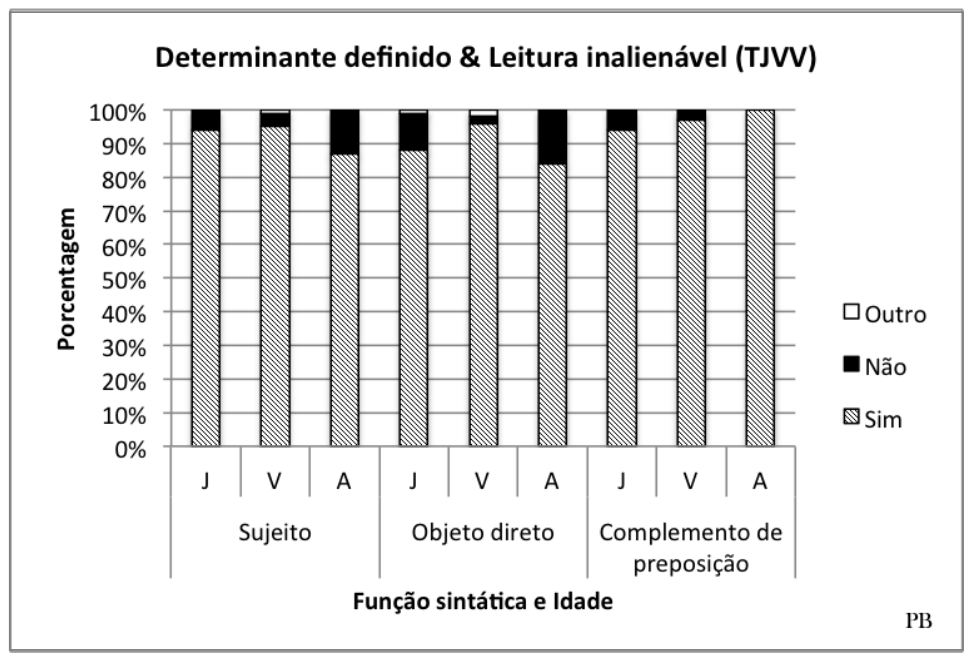

Legenda: J crianças mais jovens

$\mathrm{V}$ crianças mais velhas

A adultos

PB portuguës brasileiro

De acordo com o gráfico acima, nas funções de complemento as taxas de respostas esperadas variam de $84 \%$ a $96 \%$ em relação aos resultados na função de objeto direto, e de $94 \%$ a $100 \%$ com respeito aos resultados na função de complemento de preposição. No entanto, quando o sintagma possuído exerce a função de sujeito da passiva, a taxa de respostas esperadas, analisando-se os três grupos de participantes, varia de $6 \%$ a $13 \%$.

Observa-se, de acordo com a Tabela 2 abaixo, que existe uma diferença estatisticamente significativa apenas na função de sujeito da passiva e na de objeto direto - sendo esta disparidade entre a gramática das crianças mais velhas em relação a gramática adulta na primeira e na última, e entre as duas gramáticas infantis com respeito à última função sintática. 
TABELA 2 - Teste 1: valor de $p$, PB

\begin{tabular}{|c|c|c|c|}
\hline Sujeito da passiva & Jovens & Velhas & Adultos \\
\hline Jovens & - & 0,53390000 & 0,19240000 \\
\hline Velhas & & - & 0,02906000 \\
\hline Adultos & & & - \\
\hline Objeto direto & Jovens & Velhas & Adultos \\
\hline Jovens & - & 0,00229900 & 0,58780000 \\
\hline Velhas & & - & 0,00098730 \\
\hline Adultos & & & - \\
\hline $\begin{array}{l}\text { Complemento de } \\
\text { preposição }\end{array}$ & Jovens & Velhas & Adultos \\
\hline Jovens & - & 0,45250000 & 0,30590000 \\
\hline Velhas & & - & 1,00000000 \\
\hline Adultos & & & - \\
\hline
\end{tabular}

Esses resultados mostram, por um lado, que a coocorrência entre esse tipo de determinante e a leitura inalienável, de fato, é permitida em todas as gramáticas examinadas, exibindo uma preferência ainda maior na gramática adulta quando o nome possuído desempenha as funções de complemento, comprovando a hipótese assumida neste estudo.

Por outro lado, os resultados concernentes à função de sujeito da passiva parecem contrariar a hipótese adotada no presente estudo, que previa não ser possível tal relação de posse, dado que, desempenhando a função de sujeito da passiva, o nome possuído não estaria ligado ao seu possuidor sob as exigências do Princípio A.

Assume-se, portanto, que, neste caso, se trata de um problema pragmático advindo da técnica experimental, em que os participantes tentaram ser colaborativos, interpretando as sentenças como "suficientemente boas". 33

${ }^{33}$ Good enough interpretation, de acordo com Hemforth (c.p.). Neste caso, não se trata de um good enough das pesquisas de processamento, no sentido assumido por Collin Phillips. 
Conforme o Teste 2, esta seria a leitura com a qual o determinante definido poderia coocorrer em AE, independentemente da função sintática sob a qual o sintagma possuído aparece.

Em PB, embora a ocorrência de determinantes seja permitida sob qualquer uma das interpretações disponíveis, sendo o determinante definido substantivo ou expletivo, haveria uma tendência a não aceitar os dados sob o Teste 2, quando eles desempenham as funções de complemento - em que seria preferida a leitura inalienável, tal como discutido no Teste 1 acima. Já quando eles desempenham a função de sujeito da passiva, devido ao não cumprimento das exigências de ligação ditadas pelo Princípio A, ocorreria o oposto.

Com respeito aos resultados do AE obtidos neste teste, observa-se que, quando o determinante definido ocorre em um contexto alienável, a taxa de respostas esperadas - neste caso, sim - é bastante alta entre os resultados infantis e adultos, sob qualquer uma das funções sintáticas, conforme mostra o Gráfico 3 abaixo.

\section{GRÁFICO 3 - Teste 2: AE}

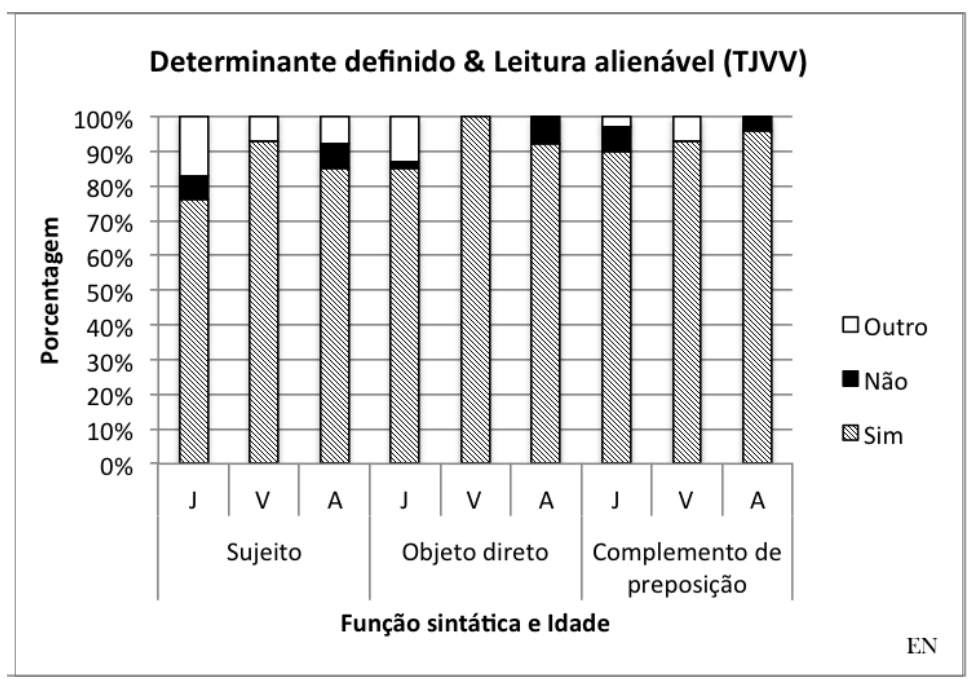

Segundo os resultados do gráfico acima, os dados de crianças mais jovens apresentam uma taxa de respostas esperadas que varia de $76 \%$ a $90 \%$ no presente teste, os dados de crianças mais velhas apresentam 
uma variação de $93 \%$ a $100 \%$ de respostas positivas e os dados adultos variam, neste caso, de $85 \%$ a $96 \%$ de respostas sim.

A análise estatística realizada comprova que, de fato, não há nenhuma diferença significativa entre as três gramáticas examinadas, como mostram os valores de $p$ na Tabela 3 a seguir, comprovando a hipótese aventada nesta pesquisa.

TABELA 3 - Teste 2: valor de $p$, AE

\begin{tabular}{|c|c|c|c|}
\hline Sujeito da passiva & Jovens & Velhas & Adultos \\
\hline Jovens & - & 0,52770000 & 1,00000000 \\
\hline Velhas & & - & 0,46150000 \\
\hline Adultos & & & - \\
\hline Objeto direto & Jovens & Velhas & Adultos \\
\hline Jovens & - & 1,00000000 & 0,25630000 \\
\hline Velhas & & - & 0,21100000 \\
\hline Adultos & & & - \\
\hline $\begin{array}{l}\text { Complemento de } \\
\text { preposição }\end{array}$ & Jovens & Velhas & Adultos \\
\hline Jovens & - & 0,29890000 & 1,00000000 \\
\hline Velhas & & - & 0,48150000 \\
\hline Adultos & & & - \\
\hline
\end{tabular}

No que concerne aos resultados referentes ao PB neste teste, percebe-se que, por um lado, há uma alta taxa de respostas esperadas - no caso, sim - em relação aos dados na função de sujeito da passiva, e, por outro, é observada uma baixa taxa de respostas esperadas - neste caso, não - em relação aos dados nas funções de complemento, como mostra o Gráfico 4 abaixo. 
GRÁFICO 4 - Teste 2: PB

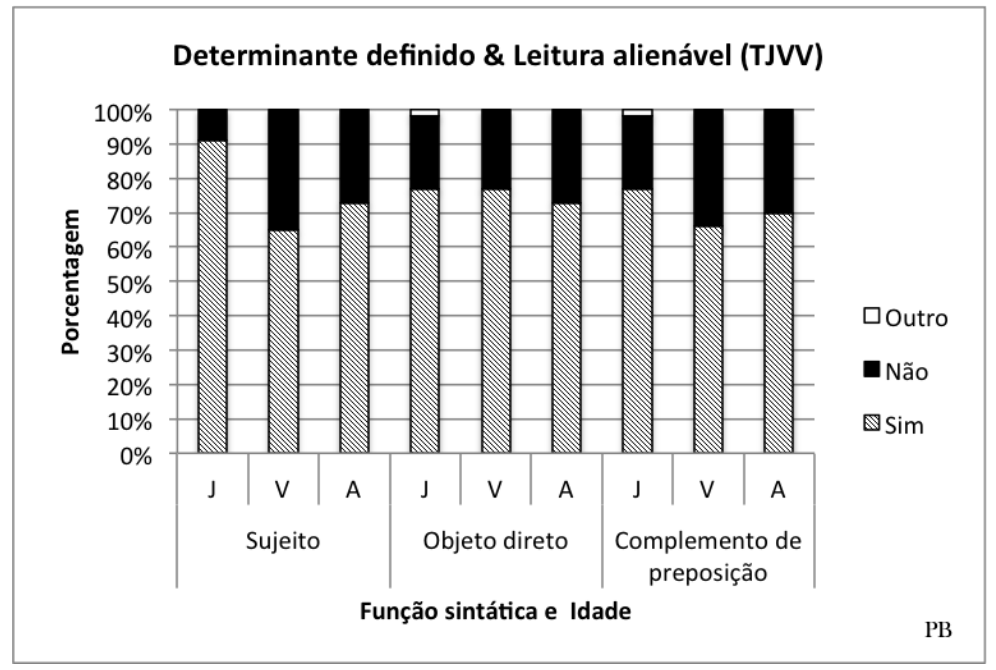

Enquanto, na função de sujeito da passiva, a taxa de respostas esperadas varia de $65 \%$ a $91 \%$ entre os três grupos etários examinados, as taxas de respostas esperadas, nas funções de complemento, objeto direto e complemento do sintagma preposicional, variam de $21 \%$ a $27 \%$ e $21 \%$ a $30 \%$ respectivamente dentre esses mesmos três grupos.

Observa-se, de acordo com a análise quantitativa aplicada, que, de maneira geral não existe uma diferença estatisticamente significativa entre as três gramáticas examinadas, exceto em relação às gramáticas infantis quando o sintagma possuído aparece na função de sujeito da passiva, como mostra a Tabela 4 abaixo. 
TABELA 4 - Teste 2: valor de $p$, PB

\begin{tabular}{c|ccc}
\hline Sujeito da passiva & Jovens & Velhas & Adultos \\
\cline { 2 - 4 } Jovens & - & 0,01483000 & 0,18300000 \\
Velhas & & - & 0,75360000 \\
Adultos & & & - \\
\hline Objeto direto & Jovens & Velhas & Adultos \\
Jovens & - & 1,00000000 & 0,60750000 \\
Velhas & & - & 0,80520000 \\
Adultos & & & - \\
\hline $\begin{array}{c}\text { Complemento de } \\
\text { preposição }\end{array}$ & Jovens & Velhas & Adultos \\
Jovens & - & 0,10940000 & 0,44190000 \\
Velhas & & - & 0,82420000 \\
Adultos & & & - \\
\hline
\end{tabular}

No presente teste, nota-se que crianças e adultos aceitam o uso do determinante definido sob a leitura alienável, tal como previsto para dados na função de sujeito da passiva, para o qual se apresentam altas taxas de respostas esperadas.

No entanto, não atendendo às previsões estipuladas para esta língua - já que se esperava uma preferência pela leitura inalienável mesmo em um contexto não favorecedor de tal leitura -, as gramáticas adulta e infantil também exibem uma alta taxa de aceite para esse mesmo uso quando se trata de dados na função sintática de complemento, o que não consiste em um problema, já que determinantes definidos substantivos também estão disponíveis em $\mathrm{PB}$, disponibilizando tal interpretação, assim como ocorre em AE.

De acordo com o Teste 3, afirma-se que, embora o pronome possessivo seja permitido sob ambas as leituras, inalienável e alienável, haveria uma preferência maior pela primeira em ambas as línguas, independentemente da função sintática desempenhada, dado que, entre os possíveis possuidores, apenas um estaria saliente na sentença-teste enquanto o outro estaria apenas presente no contexto. 
Segundo os resultados do Gráfico 5 abaixo, percebe-se que, quando o pronome possessivo coocorre com a leitura inalienável em AE, a taxa de respostas esperadas - no caso, sim - é elevada tanto nos resultados infantis quanto nos adultos, independentemente da função sintática na qual o sintagma possuído é realizado.

GRÁFICO 5 - Teste 3: AE

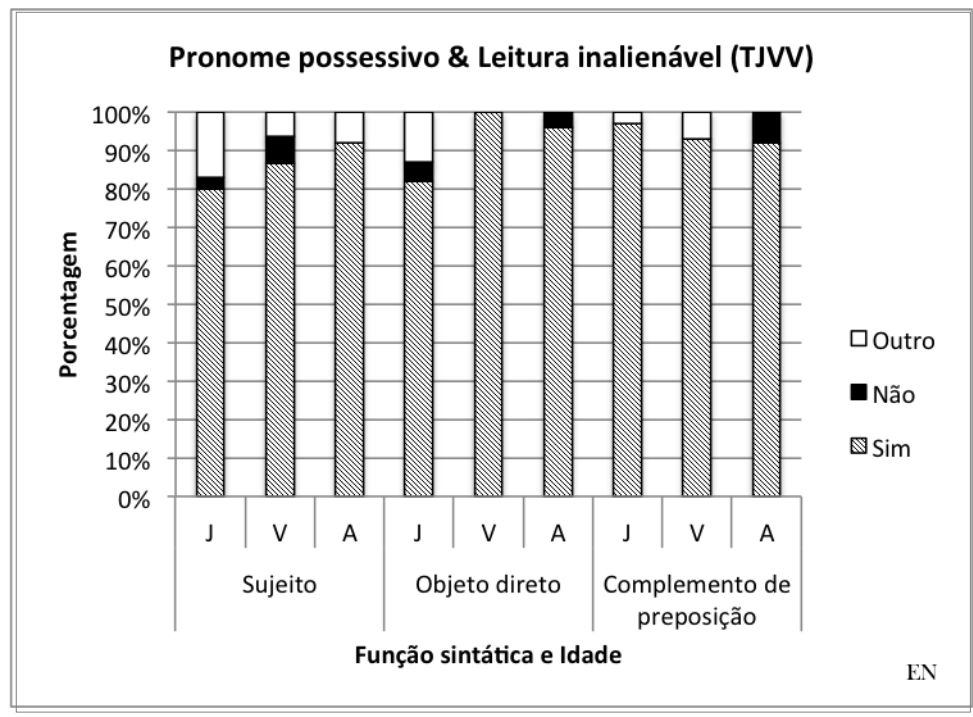

Conforme o gráfico acima, a gramática das crianças mais jovens apresenta uma taxa de respostas esperadas que varia de $80 \%$ a $97 \%$, a gramática de crianças mais velhas apresenta uma variação de $86 \%$ a $100 \%$ de respostas $\operatorname{sim}$ e a gramática adulta, de $92 \%$ a $96 \%$ de respostas positivas.

Segundo a Tabela 5 abaixo, observa-se que não há uma diferença estatística significativa entre as três gramáticas analisadas, confirmando as hipóteses da presente pesquisa. 
TABELA 5 - Teste 3: valor de $p$, AE

\begin{tabular}{c|ccc}
\hline Sujeito da passiva & Jovens & Velhas & Adultos \\
Jovens & - & 1,00000000 & 1,00000000 \\
Velhas & & - & 1,00000000 \\
Adultos & & & - \\
\hline Objeto direto & Jovens & Velhas & Adultos \\
Jovens & - & 0,29540000 & 1,00000000 \\
Velhas & & - & 0,46430000 \\
Adultos & & & - \\
\hline $\begin{array}{l}\text { Complemento de } \\
\text { preposição }\end{array}$ & Jovens & Velhas & Adultos \\
Jovens & - & 1,00000000 & 0,30950000 \\
Velhas & & - & 0,48150000 \\
\hline Adultos & & & - \\
\hline
\end{tabular}

Em relação aos dados do $\mathrm{PB}$, é possível observar que, embora haja uma oscilação maior entre as leituras em relação aos resultados do AE, como ilustra o Gráfico 6, a taxa de respostas esperadas - no caso, sim - obtidas neste teste ainda é bastante alta com respeito aos resultados infantis e adultos, independentemente da função sintática desempenhada pelo sintagma possuído. 
GRÁFICO 6 - Teste 3: PB

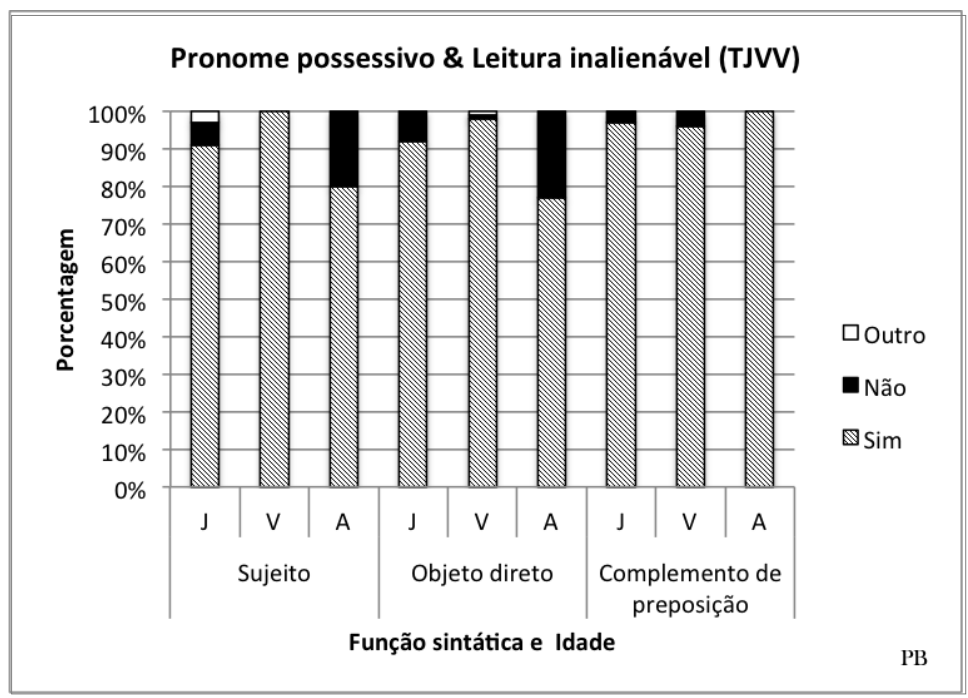

De acordo com os resultados do gráfico acima, a taxa de respostas esperadas oriunda da gramática de crianças mais jovens varia de $91 \%$ a $97 \%$, a de crianças mais velhas, de $96 \%$ a $100 \%$, e a de adultos, de $77 \%$ a $100 \%$.

Conforme a análise estatística aplicada aos dados desse teste, nota-se que existe uma discrepância significativa entre a gramática infantil e a gramática adulta nas funções de sujeito da passiva e de objeto direto, sendo a primeira entre a gramática adulta e a das crianças mais velhas e a segunda entre a adulta e ambas as gramáticas infantis, como mostra a Tabela 6 abaixo. 
TABELA 6 - Teste 3: valor de $p$, PB

\begin{tabular}{c|ccc}
\hline Sujeito da passiva & Jovens & Velhas & Adultos \\
Jovens & - & 0,16520000 & 0,30880000 \\
Velhas & & - & 0,01264000 \\
Adultos & & & - \\
\hline $\begin{array}{c}\text { Objeto direto } \\
\text { Jovens } \\
\text { Velhas } \\
\text { Adultos }\end{array}$ & Jovens & Velhas & Adultos \\
\hline $\begin{array}{c}\text { Complemento de } \\
\text { preposição }\end{array}$ & - & 0,08318000 & 0,04492000 \\
Jovens & & - & 0,00021240 \\
Velhas & Jovens & Velhas & - \\
Adultos & - & 1,00000000 & 1,00000000 \\
& & - & 1,00000000 \\
\hline
\end{tabular}

Essa diferença estatística mostra que, entre as duas leituras disponíveis, crianças apresentam uma preferência maior pela leitura inalienável na presença do pronome possessivo do que adultos, que embora também exibam essa preferência, de acordo com os dados percentuais apresentados na tabela acima, também dispõem da leitura alienável, não favorecida pelo contexto.

Em conformidade com o Teste 4, tal como discutido no Teste 3 acima, embora o uso de pronomes possessivos seja permitido sob ambas as interpretações, de acordo com a hipótese aventada neste estudo, afirmase que haveria uma preferência maior pela leitura inalienável em ambas as línguas, independentemente da função sintática desempenhada.

No que concerne à ocorrência de pronomes possessivos sob a leitura alienável em AE, observa-se que a taxa de respostas esperadas neste caso, não - segue alta na gramática adulta, enquanto se apresenta bastante inferior nos dados infantis, como mostra o Gráfico 7 abaixo. 
GRÁFICO 7 - Teste 4: AE

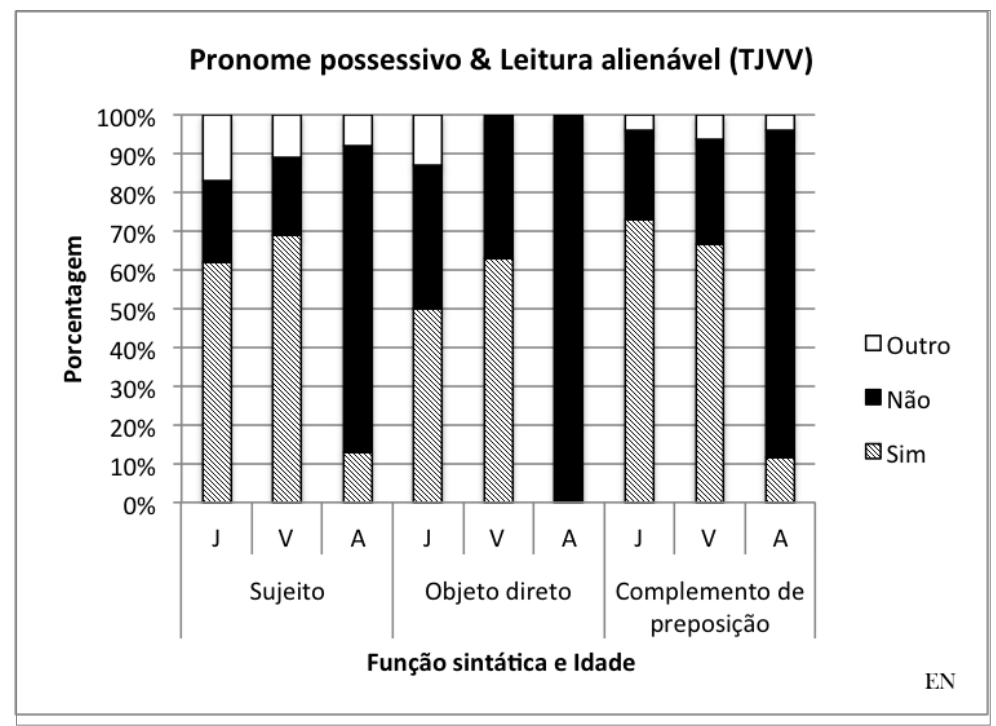

De acordo com os resultados do gráfico acima, enquanto a gramática adulta apresenta uma taxa de respostas esperadas de $79 \%$ a $100 \%$, a gramática infantil, de crianças mais jovens e mais velhas, apresenta uma taxa que varia de $20 \%$ a $37 \%$ de respostas negativas neste contexto.

Essa discrepância entre a gramática adulta e a gramática infantil pode ser confirmada na Tabela 7 a seguir, em que os valores de $p$ atribuídos a cada uma delas apresenta uma diferença estatística significativa. 
TABELA 7 - Teste 4: valor de $p$, AE

\begin{tabular}{c|ccc}
\hline Sujeito da passiva & Jovens & Velhas & Adultos \\
\cline { 2 - 4 } Jovens & - & 0,82190000 & 0,00000000 \\
Velhas & & - & 0,00000002 \\
Adultos & & & - \\
\hline Objeto direto & Jovens & Velhas & Adultos \\
Jovens & - & 0,64780000 & 0,00000015 \\
Velhas & & - & 0,00000024 \\
Adultos & & & - \\
\hline $\begin{array}{l}\text { Complemento de } \\
\text { preposição }\end{array}$ & Jovens & Velhas & Adultos \\
Jovens & - & 0,79260000 & 0,00000007 \\
Velhas & & - & 0,00001816 \\
Adultos & & & - \\
\hline
\end{tabular}

Assim, em AE, quando nomes de partes do corpo coocorrem com pronomes possessivos neste tipo de construção, observa-se que, enquanto a gramática adulta dá prioridade à leitura inalienável - ainda que não seja a intepretação favorecida pelo contexto -, a gramática infantil apresenta variação entre as duas leituras possíveis, dando preferência à leitura alienável quando mais jovem e, gradualmente à leitura inalienável à medida em que vai ficando mais velha, indo em direção à gramática alvo.

Em relação aos dados do PB, é possível observar o mesmo padrão de crescimento percentual nas taxas de respostas esperadas - neste caso, não -, exceto em relação aos dados concernentes à função de sujeito da passiva, como mostra o Gráfico 8 abaixo. 
GRÁFICO 8 - Teste 4: PB

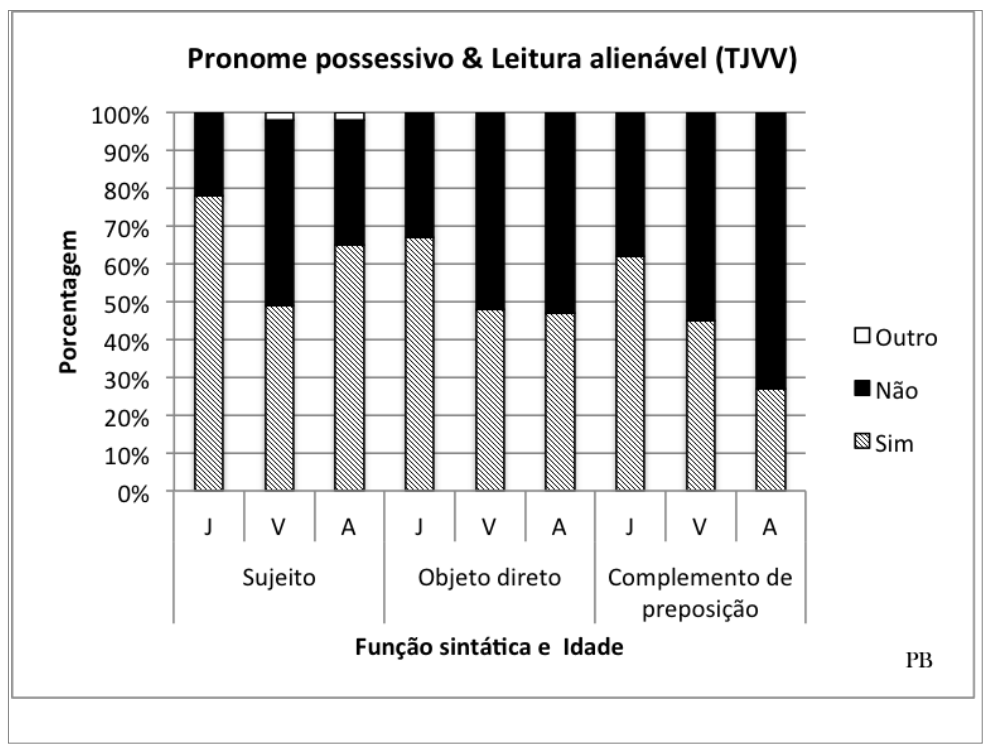

Conforme o gráfico acima, a gramática de crianças mais jovens apresenta uma taxa de respostas esperadas variando de $22 \%$ a $38 \%$, a gramática de crianças mais velhas exibe uma taxa que varia de $49 \%$ a $55 \%$ de respostas negativas e a gramática alvo expõe uma taxa de $33 \%$ a $73 \%$ de respostas não.

A análise estatística comprova que existe essa diferença significativa apenas na função de complemento da preposição entretanto, o valor de $p$ da função de objeto direto também se apresenta como bem próximo àquele esperado neste tipo de teste. No caso das outras funções, há uma diferença estatisticamente significativa apenas entre as gramáticas infantis, como mostra a Tabela 8 abaixo. 
TABELA 8 - Teste 4: valor de $p$, PB

\begin{tabular}{c|ccc}
\hline Sujeito da passiva & Jovens & Velhas & Adultos \\
\cline { 2 - 4 } Jovens & - & 0,00002135 & 0,15100000 \\
Velhas & & - & 0,08299000 \\
Adultos & & & - \\
\hline Objeto direto & Jovens & Velhas & Adultos \\
Jovens & - & 0,02313000 & 0,07478000 \\
Velhas & & - & 1,00000000 \\
Adultos & & & - \\
\hline $\begin{array}{c}\text { Complemento de } \\
\text { preposição }\end{array}$ & Jovens & Velhas & Adultos \\
Jovens & - & 0,03610000 & 0,00186200 \\
Velhas & & - & 0,09113000 \\
\hline Adultos & & & - \\
\hline
\end{tabular}

Assim, enquanto crianças mais jovens exibem uma preferência pela leitura alienável na presença de pronomes possessivos, variando de acordo com o contexto em que a sentença é apresentada, crianças mais velhas e adultos exibem uma tendência à preferência pela leitura inalienável, mesmo quando o contexto não a favorece.

\section{Conclusão}

Em relação aos resultados obtidos sob a técnica da TJVV, observou-se que, com respeito ao Teste 1, há uma baixa taxa de respostas esperadas dentre os dados infantis do AE, embora esta seja uma construção agramatical em AE adulto. Entretanto, nota-se um sensível crescimento desta ao longo das faixas etárias, demonstrando que a ocorrência do determinante definido é restrito à leitura alienável à medida que a criança fica mais velha. Os dados coletados dos sujeitos adultos exibem, por sua vez, uma taxa alta de respostas esperadas, tal como previsto.

Já em relação aos dados do $\mathrm{PB}$, adultos e crianças permitem a leitura inalienável ocorrendo com o determinante definido em qualquer uma das funções sintáticas examinadas, contrariando a hipótese assumida 
na pesquisa, que afirmava, neste contexto, não ser essa coocorrência preferencial quando o sintagma possuído desempenhasse a função de sujeito da passiva, já que as exigências do Princípio A seriam feridas. Assume-se que se trate, portanto, de um problema de ordem pragmática, em que os participantes seriam colaborativos com o experimento, interpretando as sentenças como "suficientemente boas".

Quanto ao Teste 2, observa-se uma taxa de respostas esperadas bastante alta em AE, apontando para uma preferência pela leitura alienável neste contexto, tanto no que concerne aos dados infantis quanto no que diz respeito aos dados adultos, tal como previsto.

Em relação aos resultados do $\mathrm{PB}$, percebe-se que, independentemente da função sintática exercida pelo sintagma possuído, os resultados infantis e adultos também tendem à leitura alienável, mostrando que, nesta língua, a leitura preferencial - dado que ambas estão disponíveis - varia de acordo com o contexto apresentado.

Em relação ao Teste 3, percebe-se que a taxa de respostas esperadas é elevada em ambas as línguas, mostrando que, neste contexto, há, de fato, uma preferência pela leitura inalienável tanto em AE quanto em PB.

Quanto ao Teste 4, nota-se, de maneira geral, uma alta taxa de respostas esperadas por parte dos adultos e uma baixa taxa de respostas esperadas por parte das crianças em ambas as línguas. No entanto, também é possível observar um padrão de crescimento da taxa de respostas esperadas ao longo das faixas etárias, o que mostra uma tendência à gramática-alvo.

De acordo com os resultados exibidos acima, enquanto no PB adulto haveria uma preferência pela leitura inalienável sendo veiculada por estruturas contendo determinantes definidos ou pronomes possessivos, no AE adulto, estruturas contendo pronomes possessivos favoreceriam a veiculação da leitura inalienável, enquanto estruturas contendo determinantes definidos veiculariam apenas a leitura alienável, quando presentes nomes de partes do corpo.

Ainda conforme os resultados obtidos na presente pesquisa, observa-se que no início da aquisição crianças falantes de ambas as línguas parecem aceitar ambas as interpretações sendo veiculadas por ambos os tipos de determinantes, calcando sua preferência no contexto apresentado, sendo essa preferência inicial restringida àquelas disponíveis na gramática alvo à medida que elas ficam mais velhas. 
Esses resultados, portanto, corroboram as previsões aventadas na presente pesquisa pelo fato de as estruturas, por um lado poderem ser superficialmente semelhantes e, por outro, apresentarem relações mais complexas envolvendo categorias vazias distintas, além do papel sintático-semântico do determinante e sua consequente posição estrutural.

Em consequência disso, acredita-se que a hipótese assumida de que crianças falantes de $\mathrm{AE}$ iniciariam com uma gramática semelhante àquela apresentada pelo $\mathrm{PB}$, para então, convergir para a gramática do $\mathrm{AE}$, restringindo o uso de determinantes definidos, em relação a esse tipo de construção possessiva se sustenta.

\section{Agradecimentos}

À Ruth Lopes, por tanto em tanto tempo.

À CAPES (Coordenação de Aperfeiçoamento de Pessoal de Nível Superior), pelo apoio financeiro.

\section{Referências}

AUTHIER, J.-M. The syntax of unselective binding. 1988. Dissertation (Doctoral) - University of Southern California, Los Angeles, 1988.

BARKER, C. Possessive descriptions. Stanford: CSLI Publications, 1995.

BAAUW, S. Grammatical features and the acquisition of reference. 2000. Dissertation (Doctoral) - University of Utrecht, 2000.

BAAUW, S. Grammatical features and the acquisition of reference: a comparative study of Dutch and Spanish. Revised by Jeannette Schaeffer. Glot International, Blackwell Publishing, v. 6, n. 2-3, p. 65-71, Feb-Mar. 2002.

CASTRO, A. On possessives in Portuguese. 2006. Tese (Doutorado) Universidade Nova de Lisboa, Université Paris 8, Vincennes Saint-Denis; Lisboa, Paris, 2006.

CASTRO, A. Sobre possessivos simples em português. In: Encontro Nacional da Associação Portuguesa de Linguística, XXII., Lisboa. Anais... Lisboa: APL, 2007. p. 223-237.

CHOMSKY, N. Remarks on nominalization. In: JACOBS, R.; ROSENBAUM, P. (Ed.). Readings in English Trans-formational Grammar. Waltham, MA: Ginn, 1970. 
CHOMSKY, N. Lectures on Government and Binding. Dordrecht: Foris, 1981.

DE VILLIERS, J.; ROEPER, T. Barriers, binding and acquisitions of NP-DP distinction. Language Acquisition, v. 4, n. 1-2, p. 73-104, 1995. https://doi.org/10.1080/10489223.1995.9671660.

FLORIPI, S. A. Estudo da variação do determinante em sintagmas nominais possessivos na história do português. 2008. Tese (Doutorado) - UNICAMP, Campinas, 2008.

GUÉRON, J. Inalienable possession, PRO-inclusion and lexical chains. In: GUÉRON, J; OBENAUER, H. G.; POLLOCK, J.-Y. (Ed.). Grammatical representation. Dordrecht: Foris, 1985. p. 43-86.

GORDON, P. The truth-value judgment task. In: MCDANIEL, D.; MCKEE, C.; CAIRNS, H. S. Methods for assessing children's syntax. Cambridge, MA; London: MIT Press, 1996. p. 211-232.

LICHTENBERK, F.; VAID, J.; CHEN, H.-C. On the interpretation of alienable vs. inalienable possession: a psycholinguistic investigation. Cognitive Linguistics, Berlin; New York, De Gruyter, v. 22, n. 4, p. 659689, 2011.

LONGOBARDI, G. Reference and proper names: a theory of N-movement in syntax and logical form. Linguistic Inquiry, MIT Press, v. 25, n. 4, p. 609-665, Fall, 1994.

MATHEWSON, L.; BRYANT, T.; ROEPER, T. A Salish stage in the acquisition of English determiners: 'unfamiliar' definites. In: SULA: THE SEMANTICS OF UNDER-REPRESENTED LANGUAGES IN THE AMERICAS, 2001, Massachusetts. Proceedings. Ocasional Papers in Linguistics. Massachusetts: University of Massachusetts, 2001.

MENDES, F. Estruturas possessivas: aquisição de posse funcional e posse inalienável no português brasileiro. 2010. Dissertação (Mestrado) - Universidade Federal de Santa Catarina, Florianópolis, 2010.

MENDES, F. Expressão da posse inalienável: um estudo diacrônico, 2012. Manuscrito.

MUNN, A.; MILNER, K.; SCHMITT, C. Maximality and plurality in children's interpretations of definites. In: ANNUAL BOSTON UNIVERSITY CONFERENCE ON LANGUAGE DEVELOPMENT, $30^{\text {th }}$., 2006, Somerville. Proceedings... Somerville: Cascadilla Press, 2006. p. 377-387. 
PÉREZ-LEROUX, A. T.; SCHMITT, C.; MUNN, A. Syntactic features and discourse factors in children's interpretation of definite determiners in inalienable possessions. In: ACL, 2002, Philadelphia. Proceedings... Philadelphia: Canadian Linguistics Association, 2002. p. 245-258.

PÉREZ-LEROUX, A. T.; SCHMITT, C.; MUNN, A. The development of inalienable possession in English and Spanish. In: BOK-BENNEMA, R; HOLLEBRANDSE, B; KAMPERS-MANHE, B; SLEEMAN, P. (Ed.). Romance languages and linguistic theory. Amsterdam: John Benjamins, 2002b. p. 199-216.

PÉREZ-LEROUX, A. T.; SCHMITT, C.; MUNN, A.; DEIRISH, M. Learning definite determiners: genericity and definiteness in English and Spanish. In: ANNUAL BOSTON UNIVERSITY CONFERENCE ON LANGUAGE DEVELOPMENT, $28^{\text {th }}, 2004$, Boston. Supplement to the Proceedings... Boston University, 2004.

RAMOS, E. The syntax of NPs in SLI. 1999. Dissertation (Ph.D) University of Massachussetts, 1999.

RINKE, E. A combinação de artigo definido e pronome possessivo na história do português. Estudos de Linguística Galega, Universidade de Santiago de Compostela, v. 2, p. 121-139, 2010.

ROBERTS, I. Comparative syntax. London; New York: Arnold, 1997.

SCHAEFFER, J.; MATHEWSON, L. Grammar and pragmatics in the acquisition of article systems. Natural Language and Linguistics Theory, Springer, v. 23, p. 53-101, 2005. https://doi.org/10.1007/s11049-0045540-1.

TELLIER, C. Universal licensing: implications for parasitic gap constructions. 1988. Dissertation (Doctoral) - McGill University, Montreal, Quebec, 1988.

VERGNAUD, J.-R.; ZUBIZARRETA, M. L. The definite determiner and the inalienable constructions in French and in English. Linguistic Inquiry, MIT Press, v. 23, n. 4, p. 595-652, Fall 1992.

VIANNA, T. O uso de artigo definido diante de pronome possessivo em textos portugueses do século XVI e XIX. 2004. Tese (Qualificação em Sociolinguística) - UNICAMP, Campinas, 2004. 